\title{
Atuação do Psicólogo Frente aos Transtornos Globais do Desenvolvimento Infantil
}

The psychologist's practice with children facing global development disorders

\section{José Carlos Souza}

Psiquiatra, Doutor em Saúde Mental (Unicamp). Pós-Doutor e Professor da Faculdade de Medicina de Lisboa.

Professor da

Universidade Católica

Dom Bosco, Campo Grande, MS.

Liliane Leite Fraga, Marlene Rodrigues de Oliveira,

Marli dos Santos Buchara,

Neusa Carmelina

Straliotto,

Senir Pereira do Rosário \&

Tânia Mara Rezende

Alunas do curso de Psicologia da UCDB.

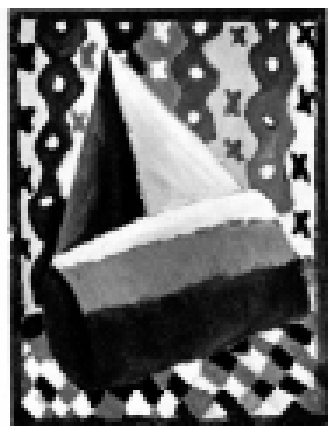

Resumo: $\bigcirc$ artigo apresenta revisão bibliográfica sobre a atuação do psicólogo frente aos transtornos globais do desenvolvimento infantil, especificamente sobre autismo infantil, síndrome de Asperger e síndrome de Rett. Inicialmente, apresenta-se uma noção do desenvolvimento infantil, e, então, abordam-se possíveis transtornos, com suas respectivas definições, etiologias, critérios diagnósticos, diagnóstico diferencial e tratamento. Durante o processo de intervenção e prevenção junto à criança, destacam-se a importância do psicólogo no tratamento e a eficácia dos recursos psicoterápicos para a melhora de qualidade de vida da criança com a síndrome.

Palavras-Chave: Autismo infantil, síndrome de Asperger, síndrome de Rett, atuação do psicólogo.

Abstract: The authors review the literature about the psychologist's performance in relation to the global disruptions of the infantile development, specifically about: infantile autism, Asperger and Rett syndromes. Firstly, this work presents the infantile development view, and then it approaches the possible disruptions with its definitions, etiologies, diagnostic criterions, different diagnostics and treatment. During this intervention and prevention process with the child, stands out the importance of the psychologist action in the treatment and the effectiveness of the psychotherapy methods that might improve the life quality of the child with the syndrome.

Key Words: Infantile autism, Asperger syndrome, Rett syndrome, psychologist's practice.

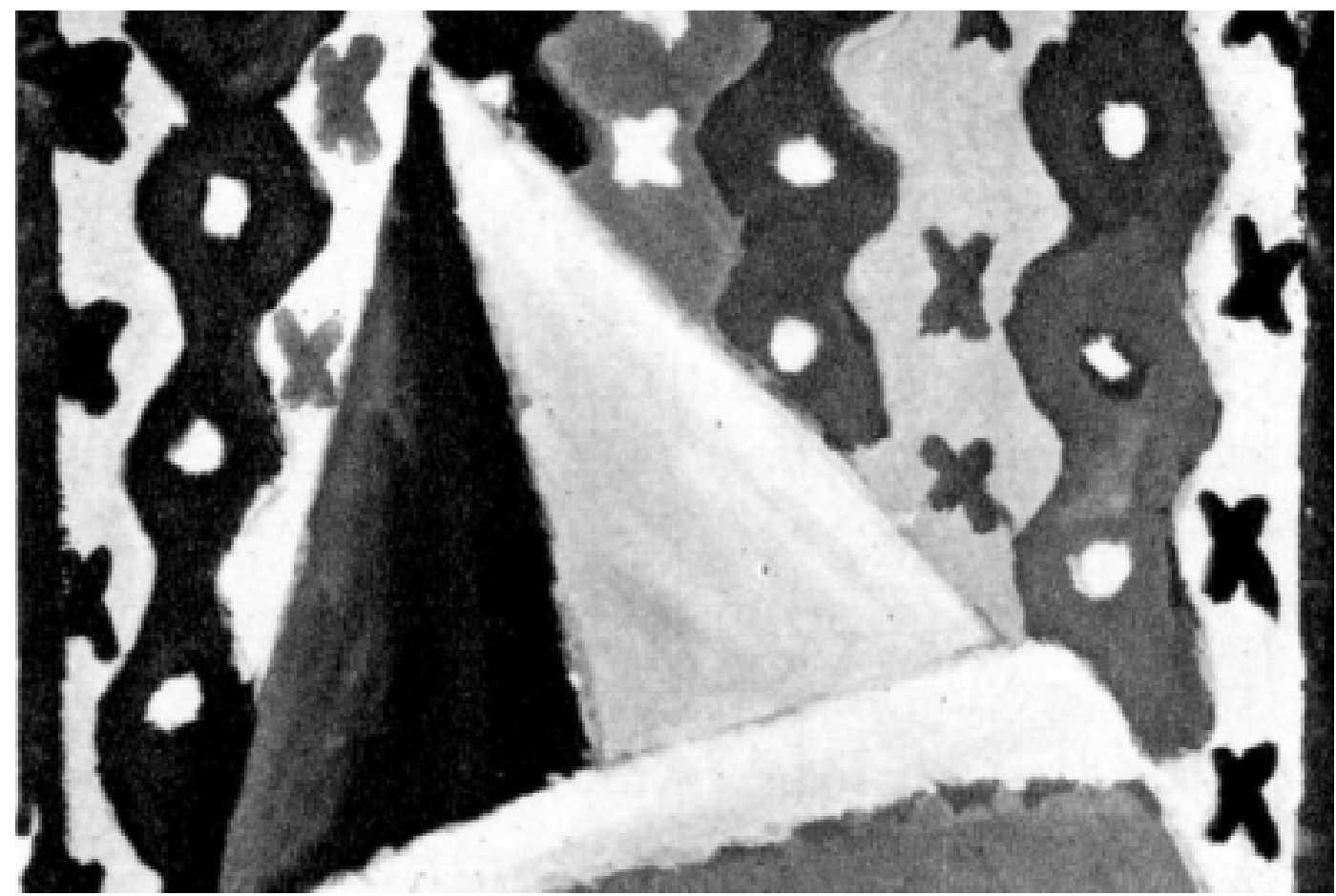

O desenvolvimento humano sempre inspirou e foi tema de amplos estudos. Atualmente, mesmo com todo o progresso da tecnologia, os estudiosos nem sempre conseguem responder às mais variadas perguntas para a compreensão do ser humano, que é muito complexo (Papalia, 2000).
Desde o momento da concepção, o homem passa por processos complicados de desenvolvimento. As mudanças ocorrem em aspectos diferentes do eu e, durante os primeiros períodos do ciclo de vida, são mais amplas e aceleradas. Como o homem é uma totalidade, todos os aspectos, físico, 
cognitivo e psicossocial, de seu desenvolvimento, estão entrelaçados, até mesmo no útero, e reagem às muitas influências internas e externas. O desenvolvimento infantil dá-se normalmente quando é sistemático, coerente e organizado. As crianças, em geral, passam pela mesma seqüência de desenvolvimento (Papalia, 2000).

A partir do século XIX, várias tendências importantes prepararam o caminho para o estudo científico do desenvolvimento infantil. Os cientistas desvendaram o mistério da concepção e começaram a argumentar sobre a importância relativa da hereditariedade e do meio (Papalia, 2000).

A compreensão dos transtornos do desenvolvimento infantil dar-se-á mediante o conhecimento do desenvolvimento infantil considerado normal. Segue-se, assim, uma visão do desenvolvimento do ciclo de vida, segundo a maioria das sociedades ocidentais modernas, analisadas por Papalia (2000) mediante estágios. O estágio pré-natal abrange o período da concepção até o nascimento. Nesse estágio, ocorre a formação da estrutura e dos órgãos corporais básicos. O crescimento físico é o mais rápido de todos os períodos, e a criança encontra-se vulnerável às influências ambientais.

A primeira infância compreende o nascimento até os três anos. O recém-nascido é dependente, porém competente. Todos os sentidos estão ativados desde o nascimento. O crescimento físico e o desenvolvimento das habilidades motoras são rápidos. A capacidade de aprender e lembrar estão presentes até mesmo nas primeiras semanas de vida. Quanto à compreensão e à fala, também desenvolvem-se rapidamente. A autoconsciência desenvolve-se no segundo ano de vida. Aproximadamente no final do primeiro ano, é que se define o apego aos pais e a outros; no entanto, o vínculo, principalmente materno, já se dá desde o nascimento.

A segunda infância é o período de três a seis anos. A força e as habilidades motoras simples e complexas aumentam. O comportamento é predominantemente egocêntrico, e a maturidade cognitiva leva a muitas idéias ilógicas acerca do mundo. A criatividade e a imaginação expressas nas brincadeiras tornam-se mais elaboradas. A independência e o autocontrole aumentam, e a família continua sendo o núcleo da vida.

A terceira infância é considerada o período de seis a doze anos. Nessa fase, o crescimento físico e o egocentrismo diminuem, enquanto a memória e as habilidades de linguagem aumentam. A autoimagem desenvolve-se, afetando a auto-estima, e os amigos assumem importância fundamental.
Conhecido esse desenvolvimento da criança, é possível, então, observar quando ocorre um desvio. É nos primeiros anos de vida que os transtornos invasivos do desenvolvimento se manifestam, transtornos esses freqüentemente associados a algum grau de retardo mental (Ellis, 1996).

\section{Transtornos Invasivos do Desenvolvimento}

Os transtornos invasivos do Desenvolvimento, classificados no Manual Diagnóstico Estatístico de Transtornos Mentais (DSM-IV), da Associação Americana de Psiquiatria (APA, 1995), caracterizamse por prejuízo severo e invasivo em diversas áreas do desenvolvimento: habilidades de interação social recíproca, de comunicação e atividades estereotipadas.

Em geral, os transtornos incidem sobre múltiplas áreas do desenvolvimento, aparecem precocemente e provocam disfunção persistente.

O DMS-IV (1995) inclui os seguintes transtornos na categoria de transtornos invasivos do desenvolvimento: autismo infantil, síndrome de Asperger, síndrome de Rett, transtorno desintegrativo da infância e transtorno invasivo do desenvolvimento sem outra especificação. No entanto, este trabalho deter-se-á nos mais comuns e de maior importância para a prática clínica.

\section{Autismo Infantil}

O autismo infantil apresenta grandes dificuldades no diagnóstico, uma vez que engloba, dentro dos conceitos atuais, várias doenças com diferentes quadros clínicos que têm como fator comum o sintoma autístico. Segundo Gillberg (1990, apud Schwartzman, 1995), o autismo é considerado uma síndrome comportamental, com etiologias e curso de um distúrbio de desenvolvimento, caracterizado por um déficit social visualizado pela inabilidade em relacionar-se com o outro, usualmente combinado com déficit de linguagem e alterações de comportamento.

Historicamente, em 1906, Plouller (apud Gauderer, 1997), introduziu o adjetivo autista na literatura psiquiátrica.

Em 1943, Leo Kanner, um psiquiatra infantil da Jonh Hopkins University (E.U.A.), descreveu um grupo de crianças gravemente lesadas, que tinham como característica comum a incapacidade de relacionar-se com as pessoas. Posteriormente, ele passa a chamar a síndrome de autismo infantil.

A etiologia no autismo associa-se a vários fatores: lesões neurológicas, rubéola congênita, 


\author{
"O surpreendente \\ vocabulário daqueles \\ que falam, sua \\ excelente memória, \\ que Ihes permite \\ recordar sucessos de \\ vários anos antes, sua \\ fantástica memória \\ mecânica para as \\ poesias e nomes e sua \\ facilidade para \\ recordar \\ minuciosamente \\ formas completas e \\ seus derivados \\ indicam que há uma \\ clara inteligência, no \\ sentido corrente do \\ vocábulo"
}

Kanner fenilcetonúria, esclerose tuberosa e síndrome de Rett. As crianças apresentam, ainda, evidências de complicações perinatais. Alguns dos indivíduos autistas têm convulsões em algum momento da vida.

A incompatibilidade imunológica entre a mãe e o embrião ou feto pode contribuir para o autismo. Irmãos de indivíduos autistas podem ser afetados por transtorno autista. Outros achados incluem um número diminuído de células de Purkinje no cerebelo, resultando em anormalidades da atenção, excitação e processos sensoriais (Kaplan, 1997).

O diagnóstico do autismo infantil, baseado no DSM-IV (1995), é caracterizado por um comprometimento acentuado no uso de múltiplos comportamentos não-verbais, tais como: contato visual direto, expressão facial, posturas corporais e gestos para regular a interação social e acentuado fracasso em desenvolver habilidades, com os pares, apropriadas ao seu nível de desenvolvimento. Existe uma falta de tentativa espontânea de compartilhar prazer, interesses ou realizações com outras pessoas, e não há reciprocidade social ou emocional. $\mathrm{O}$ comprometimento qualitativo na comunicação é acentuado pelo atraso ou ausência total de desenvolvimento da linguagem falada. Nos casos em que a fala é adequada, existe um acentuado comprometimento da capacidade de iniciar ou manter uma conversação. É comum o uso estereotipado e repetitivo da linguagem ou linguagem idiossincrásica.

"O surpreendente vocabulário daqueles que falam, sua excelente memória, que lhes permite recordar sucessos de vários anos antes, sua fantástica memória mecânica para as poesias e nomes e sua facilidade para recordar minuciosamente formas completas e seus derivados indicam que há uma clara inteligência, no sentido corrente do vocábulo" (Kanner, 1976).

As brincadeiras ou jogos de imitação social variados e espontâneos, apropriados ao nível de desenvolvimento da criança autista, encontram-se ausentes.

Normalmente, existe uma adesão aparente inflexível a rotinas ou rituais específicos e nãofuncionais. Outra característica acentuada é o maneirismo e as estereotipias motoras repetitivas. Essas crianças demonstram uma preocupação persistente com partes de objetos (DSM-IV, 1995).

Pode ocorrer um atraso ou funcionamento anormal, com início antes dos 3 anos de idade, nas áreas de interação social, linguagem para fins ou simbólicos (DSM-IV, 1995).

Os principais diagnósticos diferenciais do autismo são: esquizofrenia de início na infância, retardo mental com sintomas comportamentais, transtorno misto de linguagem receptivo/expressiva, surdez congênita ou transtorno severo da audição, privação psicossocial e psicoses desintegrativas (Kaplan, 1997).

\section{Prevenção e Tratamento}

Segundo Bereohff (apud Gauderer,1997), a complexidade do quadro de autismo e as dificuldades encontradas para se desenvolver uma estrutura em sua abordagem enfatizam cada vez mais a necessidade da multidisciplinaridade dos profissionais envolvidos nesse processo.

O psicólogo, com sua formação específica e bem definida, deve estar inserido nesse contexto, sendo também um conhecedor do desenvolvimento humano normal para ter condições de detectar as áreas defasadas e comprometidas. Ele precisa estar muito sensível às observações e relatos da família.

É fundamental que o psicólogo esteja atualizado com os trabalhos e pesquisas recentes relativos à sua especificidade para orientar a família. A sua sensibilidade diante da criança e do nível de comprometimento desta é importante para que ele saiba adequar propostas terapêuticas que realmente a beneficiem (Ellis, 1996).

É importante ressaltar que a profissão do psicólogo apresenta muitos desafios profissionais e pessoais frente aos portadores de deficiência e suas famílias. Nadja Costa (apud Gauderer, 1997), observou, em sua revisão bibliográfica, que o psicólogo pode desenvolver emoções e sentimentos face às doenças crônicas ou doenças fatais e que esses sentimentos influenciam no diagnóstico.

Em sua atuação, diz Bereohff (apud Gauderer, 1997), o psicólogo pode influir em vários níveis e desenvolver vários papéis, tais como: investigador e pesquisador, em uma equipe diagnóstica e de avaliação; psicoterapeuta, em uma abordagem individual; psicoterapeuta, em uma abordagem institucional; consultor institucional e orientador familiar.

De acordo com Windholz (apud Schwartzman, 1995), nos últimos 30 anos, vários tratamentos foram baseados em orientações teóricas diversas e de níveis de abrangência diferentes (terapias individual, psicanalítica, orientação cognitiva e outras). Esses tratamentos foram aplicados na tentativa de ajudar a pessoa com autismo a adquirir um repertório mais funcional, diminuindo, assim, os vários distúrbios de conduta. Para Windholz, atualmente, a terapia comportamental é 
considerada a mais bem desenvolvida, confiável e eficaz no atendimento da pessoa com autismo. Ornitz (apud Gauderer, 1997) diz que a melhor intervenção é uma abordagem flexível, adaptável às mudanças que ocorrem no nível de desenvolvimento.

Gauderer (1997), comentando sobre a diferença entre psicoterapia, psicanálise e orientação, salienta que todas as técnicas visam a ajudar o indivíduo. Todas têm suas vantagens e limitações. É importante que o psicólogo, em sua atuação, desenvolva uma terapia diferenciada para atender necessidades específicas, pois cada pessoa, apesar de semelhante, é única.

O uso de medicamentos faz-se necessário, embora nenhuma droga se tenha mostrado específica para o transtorno autista. "Estudos do tratamento farmacológico são complicados, pois esta síndrome inclui uma expressão multifatorial, falta um padrão de desordem" (Volkmar, 2001).

De acordo com Gauderer (1997), os pais que têm filhos com problemas sofrem. Isso é inevitável e sem exceção, e sofrem tanto mais quanto maior for a problemática do filho, a dificuldade de tratamento, a cronicidade do processo e também quanto maior for seu nível de sensibilidade. $O$ psicólogo ajuda os pais a compreenderem, discutirem, entenderem, além de trazer à tona sentimentos universalmente presentes em todos aqueles que têm filhos com problemas, ou seja, negação, culpa, frustração, impotência, ressentimento, raiva, rejeição, além de fantasias diversas.

O método TEACCH, que em inglês significa tratamento e educação para criança autista ou com problemas relacionados à comunicação, foi desenvolvido em 1996, sob a coordenação de Eri Schopler, na Universidade da Carolina do Norte. Através desse método, o psicólogo preocupa-se em envolver os pais como co-terapeutas e colocálos como grandes agentes no desenvolvimento dos filhos, realizando um trabalho individual para cada criança, nos níveis de diagnóstico, atividades domiciliares e educação especial em escolas e grupos. O psicólogo solicita dos pais colaboração referente à troca de apoio emocional terapeuta/ pais, e também atuação mútua na defesa dos direitos sociais das crianças autistas, entre eles a criação de serviços de qualidade a preços acessíveis (Gauderer, 1997).

\section{A Criança Autista em Escola Regular}

Ellis (1996), em seu trabalho sobre autismo, aborda a questão da criança autista e o período em que a mesma se encontra em idade escolar. Destaca que é improvável que haja um atendimento especializado disponível em cada jurisdição escolar para atender as necessidades das crianças autistas e que nem sempre o atendimento especializado é a opção preferida; crianças que são levemente autistas ou que são intelectualmente capazes podem ter mais a ganhar em um estabelecimento integrado, desde que suas necessidades especiais sejam reconhecidas e acomodadas. Mesmo as crianças menos capazes podem beneficiar-se, ficando junto de crianças sociáveis, com outras dificuldades de aprendizado, desde que, uma vez mais, métodos bem elaborados e explícitos de ensino as habilitem a obter benefícios.

Infelizmente, muitas crianças autistas com severas dificuldades de aprendizado estão em estabelecimentos em que suas necessidades não são reconhecidas e onde elas causam consideráveis problemas de manejo ao professor e à sala. Nestes casos, a melhor solução é o encaminhamento para um atendimento especializado (Ellis, 1996).

\section{Síndrome de Asperger}

A síndrome de Asperger "caracteriza-se pelo mesmo tipo de anormalidades qualitativas de interação social recíproca que tipifica o autismo, junto com repertório de interesses e atividades restrito, estereotipado e repetitivo" (OMS,1992).

É considerada como o transtorno mais evoluído sobre o continuum autístico. Essa síndrome foi descrita pelo médico austríaco Hans Asperger em 1944, nomeando-a "psicopatia autista". Segundo Kaplan (1997), a descrição original inclui pessoas com inteligência normal e sem atraso no desenvolvimento da linguagem, porém com comprometimento da interação social e estranheza de comportamento.

A causa desta síndrome é desconhecida, mas estudos familiares sugerem uma possível relação com o transtorno autista, o qual considera hipóteses genéticas, metabólicas e perinatais (Kaplan, 1997).

Nas anormalidades qualitativas de interação social, percebem-se peculiaridades no comportamento não-verbal, falha no desenvolvimento de relações com seus pares em idade, falta de interesse espontâneo com outros, falta de reciprocidade emocional ou social (Kaplan, 1997).

As crianças apresentam comportamentos repetitivos e estereotipados e reagem de forma inflexível a mudanças de rotina. De acordo com o DSM-IV (1995), não existe um atraso significativo na linguagem. O bom desempenho na fala é, em geral, 
apenas aparente, uma vez que utilizam as palavras e frases de forma estereotipada e repetitiva. A linguagem é automática e pouco espontânea.

Quanto ao diagnóstico diferencial, o DSM-IV (1995) inclui o transtorno autista, o transtorno invasivo do desenvolvimento sem outra especificação e, em pacientes que se aproximam da idade adulta, transtorno da personalidade esquizóide.

\section{Prevenção e Tratamento}

Sendo a síndrome de Asperger considerada como um transtorno mais evoluído do que o autismo infantil, tendem a ser benéficas para o tratamento algumas das mesmas técnicas usadas para o transtorno autista.

"A avaliação diagnóstica de uma pessoa incapacitada deve ser centralizada nas suas possibilidades, isto é, na sua capacidade de realização, independentemente de sua limitação

física, intelectual ou socioemocional"

Amiralian
Além da intervenção que o psicólogo faz junto à criança e à família, já citada no autismo infantil, o trabalho de orientação e acompanhamento é essencial aos professores e profissionais que atendem as crianças nos casos de problemas de aprendizagem, onde são indicadas salas de recuperação para fornecer explicação e revisão individualizadas.

Amiralian (1986) aborda a atuação do psicólogo nos casos de excepcionalidade e enfatiza que, nesse campo, o psicólogo deve ter conhecimento e compreensão do desenvolvimento e aprendizagem da criança, ser conhecedor dos efeitos produzidos pela incapacidade no desenvolvimento afetivo, perceptivo, motor e cognitivo. "Uma outra tarefa a que o psicólogo pode ser chamado é para a avaliação diagnóstica da criança" (Amiralian, 1986, p.66).

"A avaliação diagnóstica de uma pessoa incapacitada deve ser centralizada nas suas possibilidades, isto é, na sua capacidade de realização, independentemente de sua limitação física, intelectual ou socioemocional" (Amiralian, 1986, p.68).

\section{Síndrome de Rett}

A síndrome de Rett é uma condição clínica descrita inicialmente por Andréas Rett, em 1966, que afeta pacientes do sexo feminino, instalando-se um quadro de deterioração global e progressiva.

No Brasil, os primeiros casos foram identificados por Rosemberg e colaboradores, que publicaram suas observações em 1986 e 1987 (apud Schwartzman, 1994). afeta exclusivamente meninas, sendo que os poucos

relatos sobre o acometimento em meninos referem-se a casos atípicos com manifestações parciais, que não representam, necessariamente, a mesma condição. O primeiro caso de criança do sexo masculino com cariótipo XY com sinais e sintomas considerados típicos da síndrome de Rett foi atendido em 1995, no Brasil (Schwartzman; Souza; Faiwichow; Hercowitz, 1998). Apesar de esse menino atender aos critérios utilizados para o diagnóstico, não foi possível fechar o diagnóstico de síndrome de Rett, uma vez que o diagnóstico definitivo dessa condição dá-se após acompanhamento de alguns anos. Mesmo que esse diagnóstico não venha a ser confirmado, o caso continua sendo de grande interesse.

A razão pela qual o sexo feminino é mais afetado não foi esclarecida. No que diz respeito aos aspectos genéticos, a concordância entre gêmeas monozigóticas é de 100\%. O mecanismo de transmissão também não é conhecido.

A causa do transtorno de Rett é desconhecida. $\mathrm{O}$ desenvolvimento inicial, aparentemente normal ou quase normal, é seguido por um curso deteriorante, por perda total ou parcial das habilidades manuais adquiridas e da fala e com uma desaceleração do crescimento do crânio (Kaplan, 1997).

Muitos estudos têm sido desenvolvidos para investigar a etiologia da síndrome de Rett, sendo vários deles voltados para a etiologia genética, embasados em três hipóteses principais: "mutação ligada ao " $\mathrm{X}$ ", onde o cromossomo $\mathrm{X}$ alterado poderia ser de origem paterna ou materna; mutação no zigoto, sendo que, nesse caso, os genitores não apresentariam qualquer alteração cromossômica; inativação completa do cromossomo $X$, o que complicaria o fato de as mães de meninos com a síndrome serem assintomáticas" (Zoghbi ; Percy ; Schultz ; Fill, 1990).

Considerando os critérios do diagnóstico, segundo o DSM-IV (1995), o desenvolvimento pré-natal e perinatal nos primeiros 5 meses é aparentemente normal.

Na maioria dos casos, o início é entre 7 e 24 meses de idade, quando se percebe uma desaceleração do crescimento craniano, perda do envolvimento social, aparecimento de marcha ou movimentos do tronco fracamente coordenados e grave comprometimento do desenvolvimento da linguagem expressiva ou receptiva, com severo retardo motor. $O$ aspecto mais característico é uma perda de movimentos propositais das mãos e das habilidades motoras manipulativas finas adquiridas. As características associadas incluem crises epilépticas, respiração irregular com episódios de hiperventilação e escoliose. Mais tarde, com a 
progressão do transtorno, uma espasticidade rígida pode se manifestar (DSM-IV, 1995).

As crianças com esse transtorno podem viver por mais de uma década, porém, após 10 anos do transtorno, muitas pacientes estão em cadeiras de rodas.

Inicialmente, as crianças com síndrome de Rett são diagnosticadas como autistas, devido à deficiência acentuada nas interações sociais em ambas as síndromes. Porém, existem algumas diferenças previsíveis que se desenvolvem no processo da síndrome, como a perda das aptidóes verbais, problemas respiratórios e desaceleração do desenvolvimento craniano, ausentes no autismo (DSM-IV, 1995).

\section{Prevenção e Tratamento}

A prevenção da síndrome de Retté difícil, uma vez que, na maioria dos casos, a criança apresenta um quadro normal no nascimento, não evidenciando nenhuma característica que revele um transtorno.

O tratamento que pode ser oferecido é sintomático e visa a minimizar os prejuízos, prevenir alguns e melhorar a qualidade de vida, segundo Schwartzman (apud Gauderer,1997).Dentro desse tratamento, é fundamental a atuação do psicólogo.

A indicação da terapia comportamental tem sido citada por Kaplan (1997), pois esta ajuda no controle de comportamento autodestrutivo presente na síndrome de Rett.

Para possibilitar melhor qualidade de vida à criança que se encontra num processo deteriorante, fazse necessário o trabalho do psicólogo junto à família e aos professores que atendem as crianças, acompanhando-os e esclarecendo-os sobre o desenvolvimento da síndrome. Esse tratamento poderá ser mais eficaz quando realizado com uma equipe multidisciplinar.

Proporcionar acolhida à família, no sentido de minimizar as angústias e sofrimentos, e orientá-la no tratamento com a criança, é papel do psicólogo, o qual pode fazê-lo individualmente ou em grupos, no caso de instituições. Quando se trata do atendimento institucional, o trabalho do psicólogo vem somar-se ao da equipe multidisciplinar.

\section{Conclusão}

Os transtornos do desenvolvimento infantil são extremamente debilitantes, como se pode perceber, exigindo uma dedicação especial e quase total da família e de todos os envolvidos.
O comprometimento dos indivíduos é tão complexo que fica difícil um tratamento que seja satisfatório e que funcione em todos os casos.

O conhecimento humano é limitado, desde a etiologia da doença até a intervenção, para assegurar à criança uma qualidade de vida.

O que se nota é a necessidade de destacar a atuação do psicólogo na equipe multidisciplinar, priorizando uma intervenção que vise a proporcionar às crianças excepcionais e a seus familiares uma vida mais digna, mais amena e proveitosa, considerando excepcional "o

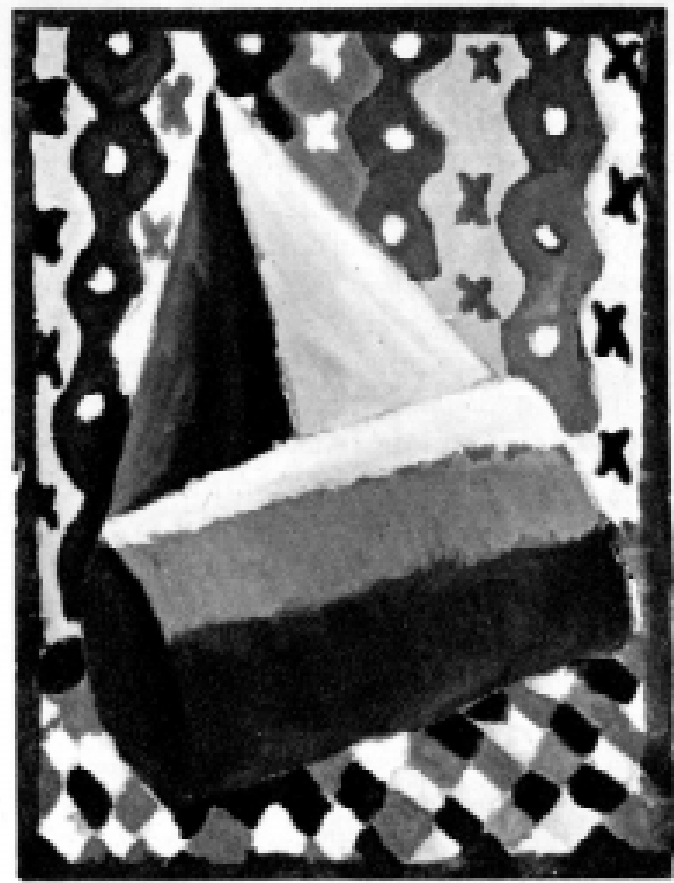

Proporcionar acolhida à familia, no sentido de minimizar as angústias e sofrimentos, e orientála no tratamento com a criança, é papel do psicólogo, o qual pode fazê-lo individualmente ou em grupos, no caso de instituições. indivíduo que se desvia, em grau arbitrário da norma, em uma determinada variável, de modo a necessitar de recursos especiais para desenvolver a sua capacidade máxima" (Kaplan, 1997).

Nesse contexto, segundo Amiralian (1978), o psicólogo também poderá fazer esclarecimentos a outros técnicos sobre as formas e condições de aprendizagem e ajustamento do indivíduo. É parte fundamental do processo de reabilitação a avaliação diagnóstica; é o ponto de partida para o estabelecimento dos programas e metas a serem atingidos.

Um trabalho de socialização é essencial, no sentido de evitar o preconceito e a discriminação ainda existentes, proporcionando uma prevenção primária, através de elucidações junto às escolas e pessoas afins. Deixar esses indivíduos viverem no 
José Carlos Souza, Liliane Leite Fraga, Marlene Rodrigues de Oliveira, Marli dos Santos Buchara, Neusa Carmelina Straliotto, Senir Pereira do Rosário \& Tânia Mara Rezende

seu mundo particular é muito cômodo e parece ser uma maneira de negar responsabilidade para com esses seres humanos e suas famílias angustiadas, necessitadas de esperança.

O trabalho do psicólogo e da equipe multidisciplinar, com a família, resulta em melhor qualidade de vida para a pessoa portadora da síndrome. Todos podem ajudar a construir esse caminho e, em especial, o psicólogo, que poderá atuar diretamente com os sentimentos, expectativas e desejos de uma vida menos dolorosa e mais suave.

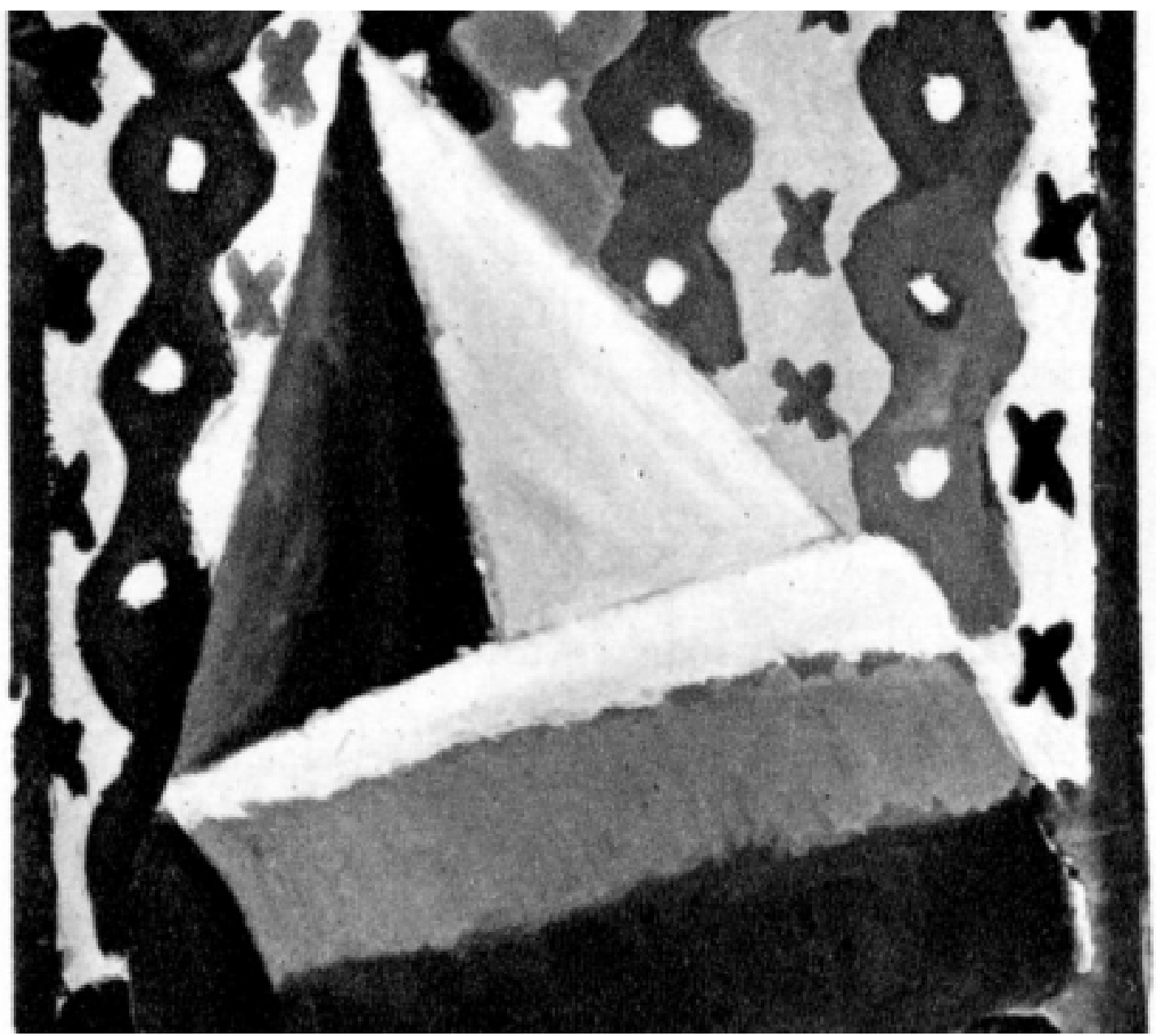


José Carlos Souza, Liliane Leite Fraga, Marlene Rodrigues de Oliveira,Marli dos Santos Buchara, NeusaCarmelina Straliotto, Senir Pereira do Rosário \& Tânia Mara Rezende Rua Theotônio Rosa Pires, 88, Vila Rosa Pires, CEP 79004-340, Campo Grande, MS. Tele/fax: (67) 325-0990

E-mail:josecarlossouza@uol.com.br www.ucdb.br/docentes/josecarlos

AMIRALIAN, M.L.T.M., Psicologia do Excepcional. vol. 8. São Paulo: E.P.U., 1978.

ASSOCIAÇ̃̃O AMERICANA DE PSIQUIATRIA. Manual de Estatística e Diagnóstica de Transtornos Mentais (DSM IV TM) 4. Ed. Porto Alegre: Artes Médicas, 1995

ELLIS, K. Autismo. Ed. Revinter: Rio de Janeiro, 1996.

GAUDERER, C. Autismo e Outros Atrasos do Desenvolvimento- Guia Prático Para Pais e Profissionais. $2^{\mathrm{a}}$ ed. revista e ampliada. Revinter, 1997.

KANNER, L. Psiquiatria Infantil. $4^{a}$ ed. Buenos Aires: Ediciones Siglo Veinte, 1976

KAPLAN, H. I. Compêndio de Psiquiatria-Ciência do Comportamento e Psiquiatria Clínica. $7^{\mathrm{a}}$ ed. Porto Alegre: Ed. Artmed, 1997.

ORGANIZAÇÃ̃ MUNDIAL DASAÚDE. Classificação dos Transtornos Mentais e de Comportamento da Cid-10. Porto Alegre: Artmed, 1992.
PAPALIA, D. E.; OLDS, S. W. Desenvolvimento Humano. Porto Alegre: Artes Médicas Sul, 2000.

AMIRALIAN, M. L. T. M. Psicologia do Excepcional. São Paulo: EPU, 1986.

SCHWARTZMAN, J. S.; ASSUMPÇÃO, F.B.J.; e colaboradores. Autismo Infantil. São Paulo: Memon, 1995.

SCHWARTZMAN, J. S. Autismo Infantil. Brasília: Coordenadoria Nacional para Integração da Pessoa Portadora de Deficiência, 1994.

SCHWARTZMAN, J. S.; SOUZA, A.M.C.; FAIWICHOW, G; HERCOWITZ, L.H. Fenótipo Rett em Paciente com Cariótipo XXY. Neuro Psiquiatria. V.56 n.4. São Paulo, dezembro, 1998.

VOLKMAR, F.R. Pharmacological Interventions in Autism: Theoretical and Practical Issues. J. Clin Child Psychol; 30 (1): , Março 2001, pp.80-7.

ZOGHBI, H.Y.; PERCY, A.K.; SCHULTZ, R.J.; FILL, C. Patterns of X Chomosome Inactivation in the Rett Syndrome. Brain Dev. 12,1990, pp.131-135.
Referências 